The nomad testis

\section{The nomad testis}

\section{P Mouriquand}

\section{Perspective on the paper by Hack et al (see page 17)}

$\checkmark$ t he abnormal position of the testis is the most common congenital anomaly of genitalia in men, with two different periods of presentation: either early in life, commonly called congenital undescended testes, or a few years later, called acquired or ascending testes. In the second group, it seems that the testis has been positioned properly at an early stage of growth, but has subsequently left its normal scrotal position to occupy the inguinal area. This group is quite controversial, as some authors considered these cases to be misdiagnoses owing to an error in physical examination. ${ }^{1}$ The cumulative experience of qualified examiners, however, suggests that this is a real phenomenon, ${ }^{2}$ which explains the increasing proportion of orchidopexies performed in late infancy. ${ }^{3}$

Browne $^{3}$ used to distinguish between the testicle that chose the wrong route (ectopic testis) and the somewhat lazy testicle that stopped on the normal route of descent before reaching its final scrotal destination (dystopic testis). It is generally agreed that these testes may finish their descent after birth, up to the age of 6 months of life. ${ }^{5}$ For a long time, retractile testes were considered to be variants of normal testis, with a suprascrotal testis that could be manipulated into the scrotum and remained there without traction until the cremasteric reflex was induced. Long-term follow-up of these patients showed that many of them will eventually present with an undescended testis, and some stated ${ }^{6}$ that retractile testes should no longer be considered to be normal variants, as they have a $32 \%$ risk of becoming ascending or acquired undescended testes. It is probably from this group of retractile testes that most ascending testes will originate, although their pathophysiology is not entirely elucidated. The common association of an abnormal testicular descent with an abnormal resorption of the processus vaginalis has intrigued surgeons for a long time, ${ }^{78}$ and could be at the origin of the reascent of the testis.' The abnormally positioned testis presenting later in childhood may be an acquired abnormality caused by a failure of the natural growth of the spermatic cord when the processus vaginalis leaves a fibrous remnant, which prevents normal elongation. ${ }^{9}{ }^{10}$ Acquired undescended testis is usually characterised by its position in the superficial inguinal pouch, closed or small open processus vaginalis and normal gubernaculum attachment. ${ }^{11}$

If we accept that the ascending or acquired testis is a defined entity, the next two questions are how common it is and how it can be treated. Several extensive clinical studies have tried to evaluate the prevalence of acquired undescended testes. Hack et $a l^{12}$ in this issue conducted a remarkable survey of three groups of male children in the Netherlands aged 6 years $(n=2042)$, 9 years $\quad(n=1038)$ and 13 years $(\mathrm{n}=353)$. In 25 children aged 6 years, 23 children aged 9 years, and 4 children aged 13 years, a diagnosis of acquired undescended testis was made, leading to a prevalence rate of $1.2 \%, 2.2 \%$ and $1.1 \%$, respectively, for acquired undescended testis. There are certain flaws in this study, as many factors may influence these data, including the quality of examination, the examiners and the history of ipsilateral or contralateral inguinal surgery. These findings should also be balanced by the fact that some socalled undescended testes may be found to be perfectly normal when the child is put under general anaesthetia. This situation certainly happens 3-4 times a year in a department of paediatric surgery. In a previous study, Hack et al ${ }^{13}$ stated that acquired undescended testes occur at about three times the rate of congenital undescended testes, accounting for the high rate of late orchidopexy. This conclusion was supported by a review of the literature by Bathrold and Gonzales, ${ }^{14}$ who evaluated the risk of ascent to be as high as $50 \%$ in cases where one testis is markedly retractile.

The next question is whether we should treat acquired undescended testis. Hack et al ${ }^{15}$ found that 63 boys with acquired undescended testes followed through puberty, 42 had a spontaneous testicular descent, although they recommended the use of human chorionic gonadotrophin in these patients in a previous paper. $^{16}$ Hormonal treatment was proved to be efficient for some, ${ }^{17}$ but not clearly effective for others. ${ }^{18}$ Everyone would agree that periodic examination of children with so-called retractile testes is mandatory. ${ }^{19}$

It remains unclear whether one is talking about the same anomaly when the abnormal position of the testis is found early or late in life. The consequences of the malposition on the testicular development may be different with regard to the risk of cancer and to fertility. Further studies are necessary to answer these questions.

Arch Dis Child 2007;92:3.

doi: 10.1136/adc.2006.098087

Correspondence to: P Mouriquand, Hopital Debrousse, Service d'Urologie Pediatrique, 29 rue Soeur Bouvier, Lyon Cedex 05, 69322 France; pierre.mouriquand@chu-lyon.fr

Competing interests: None declared.

\section{REFERENCES}

1 Rabinowitz R, Hulbert WC Jr. Late presentation of cryptorchidism: the etiology of testicular re-ascent J Urol 1997; 157:1892.

2 Docimo SG. Testicular descent and ascent in the first year of life. Urology 1996;48:458

3 Browne D. Treatment of undescended testicle. Proc R Soc Med 1949:42:643.

4 Donaldson KM, Tong SY, Hutson JM. Prevalence of late orchidopexy is consistent with some undescended tetes being acquired. Indian J Pediatr 1996;63:725-9.

5 Tomiyama H, Sasaki Y, Huynh J, et al. Testicular descent, cryptorchidism and inguinal hernia: the Melbourne perspective. J Ped Urol 2005;1:11-25

6 Agarwal PK, Diaz M, Elder JS. Retractile testis is it really a normal variant? J Urol 2006;175:1496-9.

7 Mollard P, ed. Ectopie et cryptorchidie in Précis d'Urologie de l'Enfant, In: Paris: Masson, 1984;334-44).

8 Atwell JD. Ascent of the testis: fact or fiction. Br J Urol 1985;57:474-7.

9 Clarnette TD, Rowe D, Hasthorpe S, et al. Incomplete disappearance of the processus vaginalis as a cause of ascending testis. J Urol 1997;157:1889-91.

10 Zhou Y, Takahashi G, Kono S, et al. Acquired undescended testis. Int J Urol 1998;5:504-6.

11 Meijer RW, Hack WW, van der Voort-Doedens LM et al. Surgical findings in acquired undescended testis. J Pediatr Surg 2004;39:1242-4.

12 Hack WWM, Sijstermans K, van Dijk J, et al. Prevalence of acquired undescended testis in 6-, 9and 13-year old Dutch schoolboys. Arch Dis Child 2007:92:17-20.

13 Hack WW, Meijer RW, van der Voort-Doedens LM, et al. Previous testicular position in boys referred for an undescended testis: further explanation of the late orchidopexy enigma? BJU Int 2003;92:293-6

14 Bathrold JS, Gonzales R. The epidemiology of congenital cryptorchidism, testicular ascent and orchiopexy. J Urol 2003;170:2396-401.

15 Hack WW, Meijer RW, van der Voort-Doedens LM et al. Natural course of acquired undescended testis in boys. Br J Surg 2003;90:728-31.

16 Meijer RW, Hack WW, Haasnoot K. Successful treatment of acquired undescended testes with human chorionic gonadotropin. Eur J Pediatr $2001 ; 160: 66-7$

17 Schiffer KA, Kogan SJ, Reda EF, et al. Acquired undescended testes. Am J Dis Child 1987;141:106-7.

18 Hutson JM, Hasthorpe S. Abnormalities of testicular descent. Cell Tissue Res 2005;322:155-8.

19 Belman AB. Acquired undescended (ascended) testis: effects of human chorionic gonadotropin. $J$ Urol 1988;140:1189-90. 